\title{
CONEXÕES ELÉTRICAS E TERRITORIALIDADES NO JORNALISMO BRASILEIRO
}

\author{
ELECTRICAL CONNECTIONS AND TERRITORIALITIES IN BRAZILIAN \\ JOURNALISM
}

CONEXIONES ELÉCTRICAS Y TERRITORIALIDADES EN EL PERIODISMO
BRASILEÑO

Letícia Cantarela Matheus

Universidade do Estado do Rio de Janeiro leticia_matheus@yahoo.com.br

\begin{abstract}
Resumo
O artigo apresenta uma reflexão sobre a relação entre comunicação e espaço, e jornalismo e cidade, a partir da análise empírica de dezenas de telegramas publicados em dez periódicos que circularam no Rio de Janeiro nas últimas três décadas do século XIX. O estudo procura rastrear a origem desses telegramas e investiga como os jornais e o público incorporaram a telegrafia ao circuito noticioso, buscando avaliar o papel da agência francesa Havas nesse processo, uma vez que os periódicos locais também concorreram no suprimento de notícias no Brasil. A nova tecnologia telegráfica traz também questões relativas à ocupação territorial pela comunicação, redimensionando as noções de distância, as coberturas locais e os fluxos internacionais de informação.
\end{abstract}

Palavras-chave: História do Jornalismo. Telégrafo. Território.

\begin{abstract}
This paper analyzes the relations between communication and space, and journalism and the city, from an empirical research on some dozens of telegrams published in ten journals that circulated in Rio de Janeiro during the last three decades of the 19th century. The study aims to determine the origin of these telegrams and to investigate how the newspapers and the audience have incorporated the telegraphy on news circuit, trying to assess the role of the French agency Havas in this process, once local newspapers have also contributed in the supply of news in Brazil. The new technology of telegraph also bring some problems concerning the filling of the territory by communication, resizing the notions of distance, of news coverage of local affairs and of international flows of information.
\end{abstract}

Keywords: History of Journalism. Telegraph. Territory. 


\section{Resumen}

El artículo reflexiona acerca de la relación entre la comunicación y el espacio, y el periodismo y la ciudad, a partir del análisis empírico de decenas de telegramas publicados en diez revistas que circularon en Río de Janeiro en las últimas tres décadas del siglo XIX. El estudio busca determinar el origen de estos telegramas e investiga cómo los periódicos y el público han incorporado la telegrafía al circuito noticioso, intentando evaluar el papel de la agencia francesa Havas en este proceso, ya que los periódicos locales también tenían participación en el suministro de noticias en Brasil. La nueva tecnología del telégrafo también trae problemas de ocupación territorial por la comunicación, la redefinición de las nociones de distancia, las coberturas periodísticas locales e internacionales de información.

Palabras-clave: História del Periodismo. Telégrafo. Território.

Quando a República foi proclamada no Brasil, os governos de Mato Grosso, Goiás e Amazonas só tomaram conhecimento três meses mais tarde. (Maciel, 1998) Isso ocorreu por uma razão: as autoridades daquelas províncias dependiam da chegada das informações pelo correio terrestre. Enquanto a costa brasileira já se encontrava conectada por 182 estações telegráficas desde 1886, com linhas se estendendo até Buenos Aires e Montevidéu, o interior vivia outra condição comunicacional. No início do século XX, o Marechal Rondom ainda tentava integrar o território brasileiro, levando a "civilização" aos povos indígenas e o telégrafo. O mesmo discurso integrador já acompanhava o primeiro grande projeto de instalação da telegrafia, coordenado pelo Barão de Capanema, ainda em meados do século XIX, também como termo de proteção e de união territorial. (Berthold, 1922)

A telegrafia coloca em questão a relação entre comunicação e território e expõe desigualdades históricas na distribuição dos recursos tecnológicos e midiáticos. Nesse caso, diferenças marcadas por vetores geopolíticos. O telégrafo foi a primeira tecnologia de comunicação que separou o movimento físico da transmissão de sinais, porém ainda não totalmente desterritorializada dos antigos padrões de conexão baseados nos transportes, como estradas, rios e ferrovias. (Carey, 1989, p. 202) Mas o que mais chama a atenção em relação ao tema é a permanente necessidade de justificar o interesse por uma "nova" tecnologia do passado, como lamenta Marvin (1988, p. 217). É preciso repetir o lugar especial atribuído por McLuhan (1969, p. 69) ao telégrafo, como o início da Era da Informação Elétrica. É preciso destacar a condição em rede desse tipo de comunicação, trazendo importante paralelo para os tempos atuais como faz Silva Júnior (2007). É preciso lembrar as reflexões dedicadas ao 
telégrafo feitas por Carey (1989), Sterne (2003), Nerone (2008), entre outros. E é preciso, ainda, recorrer à história econômica, à história das telecomunicações e à história social no Brasil, para encontrar informação e estabelecer um diálogo difícil de encontrar na Comunicação. ${ }^{1}$

Por esse motivo, temos investido na pesquisa empírica em jornais e documentos antigos, que indiquem a aplicação do telégrafo para o jornalismo. Este artigo é a primeira oportunidade de experimentar uma elaboração teórica preliminar com base em discussões sobre espaço e cidade, a partir do que vem sendo obtido da análise empírica. O interesse inicial sobre o uso do telégrafo no jornalismo nasceu em função da ausência de dados sobre como os periódicos e o público em geral se apropriaram da nova tecnologia. Quando a agência de notícias francesa, Havas, abriu uma sucursal no Rio de Janeiro, em 1874, e os primeiros jornais - Gazeta de Notícias, em 1875, e Jornal do Commercio, em 1877 começaram a assinar seus serviços, as primeiras estações telegráficas no Brasil já tinham sido instaladas em 1854 e eram abertas ao uso público desde 1858. (Maciel, 2001; Silva e Moreira, 2007) Portanto, nossa proposta era, em primeiro lugar, colocar em suspeição a suposta centralidade da Havas no processo de incorporação do telégrafo às práticas jornalísticas.

De fato, o envio espontâneo para os jornais parece ter sido raro num momento préHavas. Entretanto, os periódicos aparentemente nunca foram dependentes da agência para obter notícias telegráficas de dentro do país e mesmo do exterior. O monopólio da telegrafia sobre o qual frequentemente se fala diz respeito à operação da linha transatlântica, RecifeCarcavellos (Portugal), cuja concessão pertencia à Brazilian Submarine Telegraph Company. (Fernandes, 2009) Porém, dentro do território nacional, o Brasil possuía um sistema misto público-privado formado por quatro redes de telegrafia marítima, terrestre, fluvial e ferroviária. (Maciel, 1998) Em pesquisa realizada em dez diários que circularam no Rio de Janeiro entre os anos de 1870 e 1900, ${ }^{2}$ temos identificado a publicação de dezenas de telegramas não atribuídos à Havas, ainda que muitas vezes sem indicação do remetente. Alguns deles publicados simultaneamente em diferentes periódicos. É preciso explicar que

\footnotetext{
${ }^{1} \mathrm{O}$ trabalho mais completo que descobrimos sobre a telegrafia no Brasil é da historiadora Laura Maciel (1998), porém se concentra no século XX, na Comissão Rondom, e não trata do jornalismo ou de questões de comunicação social.

${ }^{2}$ São eles: Jornal do Commercio, O Fluminense, Jornal do Brasil, Gazeta de Notícias, Diário do Rio de Janeiro; Gazeta da Tarde; O Paiz; A Pátria, Diário de Notícias, A Cidade do Rio.
} 
estamos tratando das trocas efetivamente elétricas, não mais dos antigos telegramas que circulavam fisicamente como cartas e replicados em vários jornais.

\section{Os pombos de Reuters e Havas}

Em 1849, quando o então bancário e livreiro Paul Julius Reuters fundou sua primeira empresa de correspondência na Alemanha, dezesseis anos antes da famosa agência homônima, algumas linhas do seu sistema eram operadas com pombos. Charles-Louis Havas fundou, ainda em 1832, o Bureau Havas, que também se tornaria mais tarde sua agência noticiosa. O trecho Londres-Bruxelas-Paris igualmente funcionava com as aves. (Rantanen, 2007) O recurso primitivo não era obstáculo para uma vontade de comunicação em rede, antes mesmo de sua possibilidade técnica. No Brasil, antes da telegrafia elétrica, existia o telégrafo ótico, ou semafórico, composto por sinais luminosos, integrados a um sistema de bandeirolas, que ia do Morro do Castelo, na Corte, ao porto de Cabo Frio. Esse modo de sinalização arcaico não somente continuou a ser utilizado depois da adoção do telégrafo elétrico, como a ele foi integrado em 1864, o que poderíamos entender como uma convergência tecnológica do passado. Essas experiências nos obrigam a abandonar qualquer teoria que assuma um determinismo tecnológico.

Segundo Carey (1989), o inventor do software da telegrafia elétrica - o código binário formado por traços e pontos -, o americano Samuel Morse, de certa forma antecipou da ideia da "aldeia global" ao afirmar que toda a superfície dos Estados Unidos "seria canalizada por nervos para difundir com a rapidez do pensamento um conhecimento de tudo o que está ocorrendo através do território; fazendo, na verdade, uma única vizinhança de todo país." (Czitrom, 1982, apud Carey, 1989, p. 210) Em visita à França em 1837 para observar um experimento elétrico, Morse comentou:

"Se a presença da eletricidade pode se fazer visível em alguma parte do circuito que se deseja, não seria difícil construir um sistema de sinais por meio do qual a inteligência possa ser transmitida instantaneamente". (correspondência ao secretário do Tesouro, 27 de setembro, 1837, apud Sterne, 2003)

$\mathrm{O}$ argumento da transmissão da inteligência não era incomum. Assim como as atuais "autoestradas da informação" na internet, no Brasil oitocentista havia referências às "estradas 
metálicas” da transmissão elétrica. (Maciel, 1998) Também Briggs e Burke (2004, p. 140) relatam argumentos semelhantes aos atuais sobre globalização, instantaneidade e contração do espaço. Barbosa (2007) descreve ainda a sensação dos contemporâneos do século XIX acerca de um mundo mais compacto:

"Graças a sua implantação nos periódicos mais importantes da cidade do Rio de Janeiro, a partir de 1874, é possível noticiar fatos do mundo ocorridos ontem e transportar até províncias longínquas do Maranhão notícias do fim do 'século das luzes' na capital da recém-criada República." (Id. ibid., p. 21)

Marvin (1988, p. 217) lembra que, antes da internet, a comunicação elétrica já alimentava a ideia de domínio sobre o espaço. As reflexões sobre a ocupação comunicacional do espaço conduzem também a pensar sobre a condição em rede da telegrafia. Como lembra Silva Júnior (2007), a ideia da malha e o modelo de negócio segmentado das agências de notícias do século XIX serve como rico parâmetro para o atual padrão digital:
"A importância das agências pode ser percebida durante toda a sua história através da ação de circular notícias. É um cenário que remonta ao século XIX, quando o interesse dado pela expansão dos mercados, do público leitor, e a potencialidade de uma rede de comunicação, o telégrafo, reúnem condições de emergência das agências na intermediação de notícias e informações" (Id. ibid., p. 2)

A relação entre a rede telegráfica e o espaço traz ainda dois outros debates: a espacialização mental do público e, mais especificamente, as definições de escala em relação ao jornalismo. Afinal, em que medida se pode falar efetivamente num jornalismo brasileiro? Seria possível pensar uma espécie de genealogia da cobertura local em oposição às coberturas nacional e internacional?

Rantanen (2007) defende que as práticas jornalísticas já começaram com um caráter transnacional, o que se aproxima, do nosso ponto de vista, de pelo menos uma implicação em torno da atual noção de rede. $\mathrm{O}$ autor questiona o paradigma da categoria nacional como referente para a construção de uma história do jornalismo. Essa reflexão é especialmente importante no Brasil, uma ex-colônia que até o final do século XIX possuía uma frágil ideia de nação e onde - talvez justamente por isso - os jornais funcionavam como espaço público privilegiado para a construção dessa mesma nação imaginada. (Menandro, 1977; Morel, 2005; Anderson, 2008) Além disso, lembremos, apenas como curiosidade, que a história do "nascimento" da atividade impressora no Brasil costuma vir acompanhada do debate acerca 
de sua nacionalidade - se o primeiro jornal foi a Gazeta do Rio de Janeiro, publicado no território brasileiro pela corte portuguesa - ou o Correio Braziliense, publicado por um brasileiro em Londres.

Rantanen (2007) propõe um deslocamento de escala do referente país para cidade na escritura de uma história do jornalismo. Isso porque, se adotarmos o princípio de que a comunicação em rede é uma característica própria à dinâmica jornalística, passamos a tratar as cidades como pontos nodais dos múltiplos circuitos noticiosos, pelo menos durante século XIX. A introdução do fator cidade significa pensá-la não somente como centro de poder, como as capitais, mas principalmente como centro comercial, o que as leva a ser também centros noticiosos.

No Brasil, tínhamos a Corte do Rio de Janeiro como grande centro atrativo e também difusor de notícias, além de Ouro Preto, capital de Minas Gerais até 1897 e também Recife, de onde partia o cabo transatlântico. Essas cidades integravam uma economia da informação no Brasil de modo privilegiado, como centros de transmissão, como nós da rede, não apenas como origem das notícias locais ou de interesse nacional, mas também como pólo atrativo. Embora seja difícil imaginar um impacto noticioso restrito ao Brasil e a Portugal, essas cidades tinham, pelo menos, grande volume de trocas com o Cone Sul. Embora não tenhamos realizado uma pesquisa quantitativa, encontramos telegramas de Buenos Aires e Montevidéu diariamente nos jornais do Rio de Janeiro.

A conexão telegráfica com o Sul da América foi impulsionada durante a guerra contra o Paraguai (1864-1870), quando foram instaladas as linhas que cruzaram as fronteiras ao Sul do país. O professor argentino Ariel Sar (2012) chega a dizer que aquela foi a primeira "guerra midiática" da América Latina, tamanha a importância tática do telégrafo.

Rantanen (2008) chama as grandes metrópoles de operadores globais do sistema noticioso, o que não devia ser o caso das cidades brasileiras. Embora não chegassem a ser operadoras globais, certamente as cidades litorâneas tinham prevalência sobre o interior, onde o telégrafo não havia se capilarizado, com exceção talvez de Minas Gerais. Essa circunstância criava não apenas uma desigualdade tecnológica, mas também temporal. Enquanto as principais cidades do litoral brasileiro entravam num circuito de trocas telegráficas instantâneas em nível transcontinental, as informações do interior continuavam a chegar e a circular pelos meios de transporte, o que revela um modelo geopolítico de comunicação 
baseado na dicotomia interior/litoral. Portanto, não se pode reduzir a história do jornalismo ao recorte nacional/internacional ou local/nacional, sem acrescentar outros recortes que interceptam esse paradigma.

Para Carey (1989), o intercâmbio informacional em nível transnacional ao longo do século XIX se deu mais entre cidades conectadas pelo telégrafo do que entre países. Não estamos ignorando que as cidades pertençam aos países e que dentro deles encontrem suas trocas mais intensas na construção cultural. Apenas estamos considerando que as práticas jornalísticas não podiam ser "nacionais" num sentido excludente sem considerar outras dinâmicas, sobretudo após a interconexão promovida entre algumas cidades pela telegrafia, o que ocorria de modo pontual e desigual, implicando múltiplas temporalidades e também múltiplas noções de distância comunicacional.

Segundo Carey (ibid.), alguns dos intercâmbios frequentes antes do telégrafo foram deslocados no tempo e no espaço, ao tornar a troca instantânea e ao liberá-la do parâmetro do transporte. O espaço tanto condiciona quanto é condicionado pela trama tecnológica e cultural. O telégrafo ainda acompanhava o traçado geográfico das ferrovias, cujas linhas eram construídas em terrenos mais ou menos favoráveis, e dos cabos marítimos, que podiam ser estragados pelas intempéries climáticas. Mas certamente o telégrafo já era bem mais livre do espaço físico do que o tipo de comunicação que necessitava do deslocamento por navio, trem ou mula nas estradas. "O telégrafo torceu e alterou, mas não deslocou, os padrões de conexão formados pela geografia natural; pelo rio e pelas primitivas trilhas de caminhada e de cavalo e depois pelas estradas de terra, as pontes de madeira e os canais." (Id. ibid. p. 202) Isto é, a transmissão telegráfica estava longe de anular o parâmetro da comunicação do movimento dos corpos - uma carta, um jornal impresso, um moleque de recados - mas acrescentava a ele uma nova economia de sinais elétricos.

\section{Circuito elétrico de notícias}

O telégrafo pode ter projetado a Havas no país, mas, ao mesmo tempo, parece ter incentivado as trocas locais entre os periódicos. Rastreamos telegramas publicados em jornais do Rio de Janeiro para verificar de onde partiram. Nos primeiros anos, as transmissões ficavam limitadas a um espaço territorial relativamente estreito e, mesmo depois da ampliação

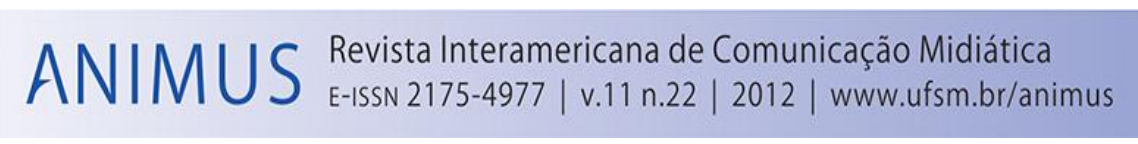


da rede até o Sul, continuavam basicamente circunscritas ao litoral, circuito que o tráfego marítimo já fazia, transportando apenas de forma mais lenta os malotes dos correios e recados em geral.

Em 1866, foi inaugurado o cabo transatlântico, permitindo a troca de dados entre América e Europa (Maciel, 2001, p. 132). Somente após a configuração desse cenário técnico, em que as transmissões transcontinentais se tornaram possíveis, é que a Havas instala sua sucursal no Brasil e finalmente os jornais começam a contratar seus serviços. Porém as informações de diversas naturezas continuariam a circular pelos antigos meios: os correios por mar e terra -, os viajantes nas estradas, nas ferrovias, os navios e a até a telegrafia semafórica, compondo um sistema comunicacional que transitava entre o transporte físico e a nascente comunicação elétrica.

De acordo com a Repartição Geral de Telégrafos (RGT), o tráfego elétrico no Brasil começou com apenas 233 telegramas enviados no primeiro ano, em 1852. No início do século seguinte, em 1909, o fluxo já havia chegado a mais de 4 milhões de transmissões por ano somente pela rede estatal, sem contar com as linhas privadas das estradas de ferro, a linha submarina costeira da empresa inglesa Western Telegraph Company, e ainda as linhas com extensão geográfica mais limitadas da também privada Amazon Telegraph Company. Assim, funcionava um sistema público-privado, em que alguns trechos e estações eram operados conjuntamente. O cabo transatlântico, que ia de Portugal a Recife, era operado pela Brazilian Submarine Telegraph and Cable Company.

Algumas estações telegráficas, como as das capitais, possuíam um tráfego de mais de 3 mil telegramas por mês. Com a maior das quatro extensões de rede, a RGT teve um volume de tráfego de 383.147 telegramas no ano de 1881. Dez anos mais tarde, esse volume cresceu cerca de duas vezes e meia. Foram 1.001.535 trocas telegráficas em 1891, ficando esse volume estável até a virada do século. Desse total, apenas um pequeno percentual representava correspondência externa, o que reforça a ideia da prevalência do interesse pelas informações internas. Entretanto, mas não é possível distinguir, desse montante, o volume de telegramas destinados aos jornais ou trocados entre eles.

As inúmeras regulamentações pelas quais passou o serviço tentavam equacionar, entre outros problemas, a questão tarifária, ponto especialmente sensível num país de dimensões continentais. Era preciso também ajustar as tarifas aos diferentes territórios na América Latina 
e às legislações dos países de outros continentes pelos quais passavam os cabos. Em 1860, um telegrama simples, de até 20 palavras, custava 80 réis. Em 1906, já havia inflacionado para 100 réis por palavra dentro de um mesmo estado. O valor da transmissão da palavra podia chegar a 500 réis se tivesse que atravessar cinco ou mais estados brasileiros. (Brasil, 1909) Pelo menos nos Estados Unidos, sabe-se que o custo operacional marítimo era maior que o terrestre. (Fernandes, 2009) Como dissemos incialmente, tanto o estímulo à iniciativa privada quanto o investimento na rede pública da RGT estavam relacionados ao discurso de integração nacional, ao "fortalecimento do Império"; ao projeto de "derrubar fronteiras geográficas", de fazer as ideias circularem pelos lugares mais distantes pelo "fluído elétrico".

O primeiro impacto que pôde ser sentido no Jornal do Commercio depois que ele contratou a Havas em 1877 é que o periódico deixou de publicar, em suplemento quinzenal, a correspondência acumulada da Europa, o que vinha fazendo desde os anos 1840. (Matheus, 2011) Entretanto, três práticas exercidas no período posterior à instalação da Havas ajudam a desmistificar sua participação no circuito de informação: a troca sistemática de telegramas entre diferentes redações; a publicação de telegramas creditados a outros jornais; e a publicação simultânea do mesmo telegrama em diversos diários espalhados pelo território brasileiro.

São inúmeros os exemplos de informações creditadas a outros periódicos, principalmente aos pequenos semanários do interior, cujos redatores deviam se preocupar em mandar os telegramas noticiosos para as "redações irmãs", principalmente as da capital, talvez porque isso trouxesse prestígio para suas próprias folhas e porque, afinal, o poder estava centrado no Rio de Janeiro, esfera onde os jornais poderiam dialogar com as autoridades da recém-criada República.

Ouro Preto, 24

O engenheiro Grey Tavares assignou hoje pela Companhia Industrial de Ouro Preto o controle para o serviço de illuminação electrica d'esta capital. Grande animação da população.

Prepara-se manifestação ao dr. Governador e às Companhias Industrial e Construtora da nova cidade de Ouro Preto - Redacção do Repórter.

(Diário de Notícias, 25/07/1890, p. 1)

O Repórter era um semanário de Ouro Preto, então capital da província de Minas Gerais. A cidade não fica tão distante do Rio, apenas $391 \mathrm{~km}$, o que traz a hipótese de a informação ter chegado pelo malote do trem. É possível também que o dono de O Repórter 
tenha querido divulgar tal fato na capital da nova República e que para isso tenha se valido da rede telegráfica, principalmente porque fora inaugurada, ainda em 1868, uma linha telegráfica direta entre Rio de Janeiro e Ouro Preto. (Berthold, 1922, p. 7)

A data do telegrama e a concisão do texto indicam não se tratar de cópia da edição já impressa, mas de troca telegráfica entre as redações. Outro dado que tende a confirmar essa prática é que havia telegramas atribuídos à redação de $\mathrm{O}$ Repórter em outros jornais da capital federal, como a Gazeta da Tarde, até com a mesma data de publicação. Ou seja, o envio foi simultâneo.

Não apenas os donos dos jornais, mas também as autoridades pareciam ter encontrado um novo meio de participar dos debates públicos e do circuito de informação, como o juiz signatário abaixo, e também um anônimo Silva Campos, que podia ser inclusive o próprio telegrafista.

Sete Lagoas, 22

Carmo

Foi aqui recebido hontem, às 8 horas da noite, telegramma do Dr. Avellar, noticiando ter sido adotado o traçado da estrada de ferro Central por esta cidade - Silva Campos

Sete Lagoas, 22

Em nome do povo de Sete Lagoas, felicito o Sr. ministro da agricultura por haver determinado o traçado da estrada de ferro por esta cidade.

Festeja-se com enthusiasmo o acontecimento, erguendo-se vivas ao ministro Francisco Glicério - O juiz de paz, João Anastácio.

(O Paiz, 23/12/1890, p. 1)

O telegrama do município de Sete Lagoas, também em Minas Gerais, poderia ter chegado ao Rio de trem rapidamente, mas não há crédito de qual periódico teria sido copiado, o que leva a crer que Silva Campos e João Anastácio tenham enviado os comunicados a $\mathrm{O}$ Paiz por telegrafia. No exemplo seguinte, fica evidente que a informação chegou ao jornal carioca via elétrica, pois o Rio Grande do Sul fica a mais de 1,5 mil quilômetros do Rio de Janeiro, distância intransponível de trem em menos de 24 horas.

A illustrada redacção do Echo do Sul enviou-nos o seguinte telegramma: Rio Grande do Sul, 23

Seguiu para Santa Catharina o capitão de fragata Eduardo Wandelekock.

$\mathrm{Na}$ noite da véspera da partida recebeu uma enthusiatica manifestação do comercio e do povo rio grandense. (Gazeta de Notícas, 24/08/1890, p. 1)

É difícil afirmar sobre grau de popularidade da telegrafia. Mais ainda descobrir o nível 
de interação com os jornais. Em relatório enviado ao Ministro da Agricultura em 1891, Demétrio Ribeiro, o então diretor da RGT, João Nepomuceno Baptista, informava que o volume do tráfego telegráfico aumentara em 50\% de 1889 para 1890, mas que a receita da repartição não subira proporcionalmente devido a três fatores. Primeiro, porque houve uma redução de $30 \%$ no valor das tarifas aos "particulares" e um barateamento de $50 \%$ da tarifa para a imprensa, percentual aplicado já sobre o valor reduzido dos "particulares", categoria geral onde os jornais eram classificados. (Brasil, 1891)

Porém o maior problema, segundo Baptista, era a dificuldade de cobrar o serviço dos funcionários públicos, pois o telegrama era gratuito quando anunciado como de "serviço público". Esse tipo de queixa é uma constante na história da comunicação telegráfica na América Latina. (Baur, 1994) Além disso, quando classificado como "urgente", o telegrama do funcionário público podia "furar a fila" das transmissões, o que era motivo de reclamação dos usuários. Baptista pedia providências e dizia ter dado ordens os chefes das estações que mandassem os remetentes assinarem recibo para serem cobrados nas repartições. Pelo visto, a medida não funcionou, pois o relatório de 1909 ainda registrava a queixa do público contra os atrasos em função dos abusos do serviço público, embora o volume do tráfego dos "particulares" fosse cinco vezes maior. (Brasil, 1909)

Além da tarifa diferenciada, a imprensa contava com outro benefício. A Portaria 296 da diretoria, datada de 22 de outubro de 1890, assinada por Baptista, acatava proposta dos jornais de reduzir a tarifa e fazer a cobrança somente no destino. Na prática, isso significava que podiam ser enviadas mensagens para as redações e, se fosse de interesse delas, aí sim pagavam pelo telegrama. Se ninguém fosse buscar a mensagem, ela era descartada. Essa prática colocava os jornais em posição privilegiada como polo atrativo de informações e permitia também que uma redação se comunicasse com outras a custo baixo. A tarifa de transmissões para a imprensa seria reduzida mais uma vez, em 75\%, segundo a Lei 428 de 10 de dezembro de 1896. (Berthold, 1922, p. 24)

Foram identificados telegramas idênticos publicados simultaneamente em diferentes jornais, sem a assinatura da Havas nem de qualquer outro periódico, o que pode indicar também o envio espontâneo de telegramas aos jornais. O mais comum, entretanto, é que fossem creditados ao Jornal do Commercio, além da Havas. 
A Gazeta de Notícias publicava telegramas sem indicação de fonte, o que faz crer que pudesse se tratar do público em geral, interessado na divulgação das informações por algum motivo. Outras vezes, esse tipo de material aparecia com a assinatura "Serviço Telegráphico da Gazeta de Notícias", o que indica serem da Havas.

Por telegramma recebido ontem de Pernambuco, sabe-se que foi n'aquella
data inaugurado o tráfego da estrada de ferro Parahyba, com assistencia do
Sr. presidente da província e no meio de immenso contentamento de toda a
população, que cheia de enthusiasmo saudava os emprehendedores de tão
importante melhoramento. (Gazeta de Notícias, $11 / 08 / 1880$, p. 2 )

Fundada por Ferreira de Menezes e de propriedade de Luiz Ferreira Moura Brito, a Gazeta da Tarde, do Rio de Janeiro, tinha assinatura anual de 15 contos de réis na capital e mantinha seu escritório na Rua do Ouvidor. O jornal também mantinha, em 1890, o "Serviço Especial da Gazeta da Tarde - exterior e interior", o que novamente pode ser interpretado como sendo o contrato com a Havas. Nessa coluna, encontravam-se inúmeros telegramas internos, que podiam ser distribuídos pela própria agência francesa, embora não houvesse indicação explícita sobre isso. Por outro lado, aparecem também os telegramas atribuídos à "Redacção de O Repórter", o pequeno semanário mineiro de quatro páginas, que parecia ser um grande distribuidor de notícias da vida social e política de Minas para o Rio de Janeiro.

Em 1890, O Paiz contava com uma tiragem de 32 mil exemplares e valor avulso de 100 rés. Mantinha uma coluna "Telegrammas" com que se supõe ser o serviço da Havas, com a seguinte assinatura "Serviço especial d'O Paiz". Devido a seu prestígio, "a folha de maior tiragem e de maior circulação na América do Sul”, como se autodeclarava, também devia atrair o envio de telegramas avulsos de quem quisesse simplesmente comunicar algo publicamente. $\mathrm{Na}$ sua coluna "Telegrammas", encontram-se despachos do estrangeiro e nacionais, o que mostra que a Havas também se voltava para o circuito interno, como confirmado em inúmeros boletins nacionais com sua assinatura.

Proprietário de A Cidade do Rio, José do Patrocínio dá pistas importantes sobre a distribuição das informações naquela época. Seu jornal foi fundado em 1877 e circulou até 1893. Ele trazia a coluna "Telegrammas", na página 2, dividida em três partes: na primeira parte, os boletins do exterior e do interior, e ainda indicava entre parênteses, ao final de cada sequência, a fonte. Além da Agência Havas, o jornal frequentemente creditava os telegramas ao Jornal do Commercio. Aqueles da Havas, todos do exterior, vinham com o aviso "Serviço 
directo". Isto significava que A Cidade do Rio era contratante dos serviços noticiosos da agência internacional. Em A Cidade do Rio, todos os telegramas nacionais, e mesmo alguns de outras partes da América do Sul, vinham com a assinatura "Jornal do Commercio" entre parênteses.

Primeiro, vinham os creditados ao Jornal do Commercio. Em seguida, os da Havas, e, por fim, aqueles sem nenhuma assinatura, que deviam ser de divulgação espontânea. Bahia (2009, p. 149) confirma que A Cidade do Rio possuía, além da assinatura da Havas, um serviço particular de telegrafia e ainda um serviço especial com despachos e notícias exclusivas obtidas diretamente pelo jornal. Portanto, estamos longe de um monopólio da Havas, mesmo em relação aos telegramas estrangeiros. Além disso, o Jornal do Commercio parece ter sido mais empreendedor e ter tido papel mais central na distribuição noticiosa do que se imagina. Tanto ele, quanto as principais redações, deviam receber telegramas diretamente endereçados a eles, sem passar pela Havas.

Barbosa (2010, p. 183) afirma que o Jornal do Commercio se apresentava como portavoz dos governos e confirma que ele desempenhava a função de redistribuir as informações oficiais para os demais periódicos. E é provável que essa distribuição fosse feita por telegrafia. Exemplo da estreita relação do jornal com o poder e sua função de "assessoria de imprensa" oficial está no telegrama enviado à nação pelo ex-imperador dom Pedro II, no exílio em Portugal, sobre a morte de sua esposa.

\footnotetext{
Notícia chegadas pelo expresso de hoje:

Recebemos hontem o seguinte telegramma:

Porto, 6 de janeiro

Jornal do Commercio, Rio de Janeiro

Não podendo de prompto dirigir-nos separadamente aos muitos amigos que, do Brazil, nos enviaram a expressão de sua sympathia por occasião da irreparável perda de nossa muito cara esposa e mai, por este meio lhes endereçamos nossos cordiaes agradecimentos - D. Pedro de Alcantara - D. Isabel Condessa D’Eu - Gaston de Orleans (Correio da Noite, 07/01/1890, p. 1)
}

Como o próprio texto informa, neste caso o Correio da Noite, de Ouro Preto (MG), compilou a edição do Jornal do Commercio chegada pelo "expresso", o trem, mas o telegrama fora remetido por dom Pedro de Lisboa por telegrafia diretamente ao diário do Rio de Janeiro, encarregado de repassar a mensagem aos demais jornais. O Correio da Noite sempre dava os créditos: "Por telegramma enviado ao Jornal do Commercio", “O Paiz", "Do Diário do Rio 
Claro" (de São Paulo), “Segundo telegramma de Lisboa à Gazeta de Notícias”, o que reforça a ideia da compilação, apesar de se tratarem de telegramas muitas vezes datados do mesmo dia.

\section{Jornalismos local, nacional e internacional}

É sabido que a Havas se dedicava à cobertura internacional, mas não se pode excluí-la da produção e distribuição noticiosa local. Não sabemos se esse circuito se dava exclusivamente pela rede costeira da Western Telegraphic Company, mas certamente alguns trechos passavam pelas linhas estatais da Repartição Geral dos Telégrafos, que, além de convênio com aquela, possuía malha bem mais extensa. Por outro lado, a Western realizou gratuitamente consertos para a RGT. Por exemplo, em 1890, ela substituiu alguns trechos submersos em Santa Catarina, danificados pela passagem de um navio à deriva, provavelmente devido ao conhecimento que a Western detinha sobre esse tipo específico de assentamento de linha. Do mesmo modo, o Jornal do Commercio também assinava boletins externos, embora provavelmente não os distribuísse internacionalmente como fazia a Havas.

Ao mesmo tempo em que continuavam a compilar as folhas chegadas de navio de praticamente todas as províncias litorâneas e também por malotes de trem, os periódicos publicavam simultaneamente telegramas idênticos com mesma data e origem.

Recife, 30 de Novembro

O povo reunido em praça publica pedia pão e trabalho. Mais de 10,000 pessoas acclamarão oradores os Dr. Antero Furtado, Dr. José Braziliano e Fortunato Pinheiro. O governador garantio satisfazer o pedido auxiliado pelo presidente da intendência. Grande enthusiasmo. (do Jornal do Commercio) (Jornal do Commercio, 01/12/1890, p. 1)

Esse telegrama foi publicado no mesmo dia no Jornal do Commercio, em A Cidade do Rio (com assinatura do Jornal do Commercio) e em O Paiz, sendo que neste último o texto foi modificado e aparece sem a assinatura do concorrente Jornal do Commercio:

Recife, 30

Houve hoje grande reunião popular na praça publica. Assistiram 10.000 pessoas, pedindo trabalho. Oraram os Drs. Manoel Antero, José Braziliano e Fortunato Pinheiro, sendo muito aplaudido.

O governador garantiu providencias e é neste intuito auxiliado pelo presidente da intendência. Esta declaração produziu enthusiasmo delirante.

(O Paiz, 01/12/1890, p. 1) 
Não sabemos em que medida O Paiz recebeu outro telegrama ou se reeditou o original, e se este era do Jornal do Commercio. De qualquer forma, a assinatura "Jornal do Commercio" em A Cidade do Rio sugere que fora ele a coletar ou receber a informação, porque, quando o telegrama advinha da Havas, havia "Havas" escrito entre parênteses. Seria pouco provável que o Jornal do Commercio distribuísse telegramas para seus concorrentes, principalmente O Paiz. Quem teria distribuído esse telegrama para pelo menos três grandes jornais em circulação no Rio?

Ao final da década de 1890, o Jornal do Commercio explorava cada vez mais seu próprio serviço, priorizando o noticiário nacional e publicando, da Havas, principalmente os internacionais. Ele passa a publicar o horário preciso de recebimento dos telegramas, assinados, muitos deles, coletivamente, o que indica maior participação do público. Um mal entendido no município de Mangaratiba, no Sul fluminense, no final do período, revela a intimidade do público leitor com o sistema telegráfico e sua utilização para interferir na esfera pública e interagir com os jornais.

Mangaratiba, 9 de setembro

O telegramma daqui dirigido à Gazeta de Notícias e publicado na folha de 8 do corrente não é verdadeiro. Pompeo, que é, segundo dizem, autor do crime praticado na pessoa do Dr. Cypriano, foi preso por Giacomo Giglio na estrada de Ingahyba e não em casa de autoridade. O signatário do alludido telegramma, pois, será criminalmente chamado perante a autoridade competente, para provar o que não duvidou asseverar publicamente pela imprensa. - O subdelegado em exercício, Bernardo Vieira de Vasconcellos. (Jornal do Commercio) (Jornal do Commercio, 10/09/1892, p. 1)

Apesar da proximidade de Mangaratiba, apenas 85 quilômetros do Rio, os envolvidos nas investigações do crime fizeram uso da telegrafia para se comunicar com os diários da capital. O Jornal do Commercio ainda fez questão de marcar textualmente, pela assinatura, tratar-se de um comunicado direcionado especialmente a ele. Além disso, revela a configuração dos jornais numa rede intertextual de comunicação, que incluía a difusão de informações julgadas relevantes pelo público. Agora com a presença deste novo elemento: o telégrafo. 


\section{Considerações}

O uso do telégrafo diz respeito também à ocupação do território pela imaginação, afinal, o público passou a tomar conhecimento de acontecimentos distantes num intervalo de tempo cada vez mais curto, compondo um mapa mental do Brasil a partir do noticiário. Além de as estações telegráficas interligarem diferentes pontos, postes e fiações interferiram na paisagem das cidades e das estradas (Brasil, 1909). Do mesmo modo, também o espaço comunicacional das páginas impressas passa a incorporar cada vez mais notícias oriundas daqueles que estão fisicamente distantes.

De certo modo, o modelo de jornalismo no século XIX se caracterizava por uma forma indireta de obtenção de informação, principalmente as distantes. Porém, isso não significa que alguém não tivesse que observar a realidade e relatá-la aos jornais. Além das autoridades do Império, e depois da República, cada vez mais, personagens anônimos resolvem colaborar com os periódicos de maior prestígio.

A Corte era fonte privilegiada de notícias, mas também polo atrativo de informações que o público distante julgava ser importante difundir, até mesmo fatos banais, como uma festa numa escola em Campos dos Goytacazes (RJ), divulgada por telegrama ao Jornal do Commercio em 16 de dezembro de 1890, entre outros exemplos do que parece ser divulgação espontânea. Entre esses leitores-publicadores estavam administradores públicos, juízes, advogados, e dignitários em geral, além de muitos.

Embora a Havas tenha começado a vender seus telegramas para os jornais brasileiros em 1875, as folhas do Império já publicavam há muitos anos a coluna "Telegrammas", mas o título pode enganar. Apenas eventualmente ocorria de uma ou outra nota ser fruto efetivamente de telegrafia, quase sempre sobre movimentação portuária e preços de mercadorias, como neste exemplo:

Santos, 3 de julho

Nada se faz em café e algodão. $O$ Paulista sahio às 4 horas, com 224 sacas café 28 fardos algodão.

(coluna "Telegrammas", Jornal do Commercio, 04/07/1872, p. 1)

O boom da telegrafia aplicada aos jornais será mais tarde, após a instalação da Havas, porém não em função dela. Em vez de impor um modelo internacional, ela parece ter dinamizado e interagido com as práticas de trocas locais. Enquanto isso, as noções de 
distância no território nacional iam sendo reformuladas das antigas condições geográficas e de deslocamento, para serem integradas a um modo inédito de imaginar a distância comunicacional entre as pessoas no tempo e no espaço.

\section{Referências}

ANDERSON, Benedict. Comunidades imaginadas. São Paulo: Companhia das Letras, 2008.

BAHIA, Juarez. História da Imprensa Brasileira. Jornal, História e Técnica. Vol. 1. Rio de Janeiro: Mauad-X, 2009.

BARBOSA, Marialva Carlos. História Cultural da Imprensa. Brasil - 1900-2000. Rio de Janeiro: Mauad X, 2007.

BARBOSA, Marialva Carlos. História Cultural da Imprensa. Brasil - 1800-1900. Rio de Janeiro: Mauad X, 2010.

BAUR, Cynthia. The Foundations of Telegraphy and Telephony in Latin America. Journal of Communication. 44 (4), Autumn, 1994.

BERTHOLD, V.M. History of the Telephone and the Telegraph in Brazil - 1851-1921. New York: University of Michigan Library, 1922.

BRASIL. Repartição Geral dos Telégrafos. Memória Histórica. Rio de Janeiro: Imprensa Nacional, 1909.

BRASIL. Repartição Geral dos Telégrafos. Relatório dos anos 1889/1890. Rio de Janeiro: Imprensa Nacional, 1891.

BRIGGS, Asa; BURKE, Peter. Uma história social da mídia. De Gutenberg à Internet. Rio de Janeiro: Zahar, 2004.

CAREY, James W. Communication as culture: essays on media and sociology. Boston: Unwin Hyman, 1989.

FERNANDES, Felipe Tâmega. Telegraphs-Shrinking Economic Distances? A Preliminary Enquiry, 1870s-1912 Business Archives: Sources \& History, no. 99 (November 2009).

MACIEL, Laura Antunes. "Cultura e tecnologia: a constituição do serviço telegráfico no Brasil.” Revista Brasileira de História. São Paulo, v. 21, n. 41, 2001, pp. 127-144;

MACIEL, Laura Antunes. A nação por um fio: caminhos, práticas e imagens da "Comissão Rondon”. São Paulo: Educ, 1998. 
MARVIN, Carolyn. When old technologies were new. Thinking about electric communication in the late nineteenth century. New York: Oxford, 1988.

MATHEUS, Leticia Cantarela. Comunicação, tempo, história: tecendo o cotidiano em fios jornalísticos. Rio de Janeiro: Mauad-X, 2011.

McLUHAN, Marshall. Os meios de comunicação como extensões do homem. São Paulo: Cultrix, 1969.

MENANDRO, Heloísa Fesch. A idéia de nação e o pensamento nacionalista na imprensa da corte. 1840-1860. Dissertação de Mestrado. Rio de Janeiro: ICHF-UFF, 1977.

MOREL, Marco. As transformações dos espaços públicos: imprensa, atores políticos e sociabilidades na cidade imperial (1820-1840). São Paulo: Hucitec, 2005.

NERONE, John. "Newswork, technology, and cultural form, 1837-1920". In: ZELIZER, Barbie. Explorations in Communication and History. New York: Routledge, 2008, pp. 136156.

RANTABEN, Terhi. The Cosmopolitanization of News. Journalism Studies. 8;6, pp. 843-867, 2007.

SAR, Ariel. "La introducción de las telecomunicaciones eléctricas en el Río de la Plata." Trabalho apresentado no XI Congreso Latinoamericano de Investigadores em Comunicación (Alaic). Montevieo (UR): 2012.

SILVA JÚNIOR, José Afonso da. "Legado e espólio das agências de notícias para o jornalismo na web." Texto apresentado no XVI Encontro da Compós, na UTP, em Curitiba (PR). Anais Compós, 2007.

SILVA, Mauro Costa da, e MOREIRA, Ildeu de Castro. "A introdução da telegrafia elétrica no Brasil. (1852-1870)". Revista da SBHC. Rio de Janeiro, v. 5, n. 1, jan/jul, 2007, pp. 47-52.

STERNE, Jonathan. The Audible Past. Cultural Origins of Sound Reproduction. London: Duke University Press, 2003.

Material empírico analisado

A Cidade do Rio, outubro e dezembro de 1890;

A Pátria (Niterói-RJ), outubro de 1871;

Correio da Noite (MG), janeiro de 1890;

Diário de Notícias, julho de 1885, julho de 1890;

Diário do Rio de Janeiro, julho de 1870, abril de 1878;

Gazeta da Tarde, agosto de 1890;

Gazeta de Notícias, outubro de 1875, fevereiro de 1879, agosto de 1890; 
Jornal do Brasil, dezembro de 1891, abril de 1897;

Jornal do Commercio, setembro de 1870, julho de 1872, abril de 1877, fevereiro de 1879, julho de 1881, junho de 1883 , maio de 1887 , dezembro de 1890 , setembro de 1892 , junho de 1897, dezembro de 1899, janeiro de 1900;

O Fluminense (Niterói-RJ), maio e julho de 1888, julho de 1892, abril de 1897, julho e setembro de 1898;

O Paiz, dezembro de 1890, julho de 1892;

O Repórter (MG), agosto de 1890;

Original recebido em: 30/10/2012

Aceito para publicação em: 03/12/2012

Resumo sobre o autor

Letícia Cantarela Matheus é professora de Comunicação da Universidade do Estado do Rio de Janeiro (Uerj). Doutora em Comunicação pela UFF. 